\title{
Recent rift formation and impact on the structural integrity of the Brunt Ice Shelf, East Antarctica
}

\author{
Jan De Rydt ${ }^{1, a}$, G. Hilmar Gudmundsson ${ }^{1, a}$, Thomas Nagler ${ }^{2}$, Jan Wuite ${ }^{2}$, and Edward C. King ${ }^{1}$ \\ ${ }^{1}$ British Antarctic Survey, High Cross, Madingley Road, CB3 0ET, Cambridge, UK \\ ${ }^{2}$ ENVEO, ICT-Technologiepark, Technikerstr. 21a, 6020 Innsbruck, Austria \\ anow at: Geography and Environmental Sciences, Northumbria University, Newcastle, UK
}

Correspondence: Jan De Rydt (jan.rydt@ northumbria.ac.uk)

Received: 31 August 2017 - Discussion started: 12 September 2017

Revised: 6 December 2017 - Accepted: 22 December 2017 - Published: 9 February 2018

\begin{abstract}
We report on the recent reactivation of a large rift in the Brunt Ice Shelf, East Antarctica, in December 2012 and the formation of a $50 \mathrm{~km}$ long new rift in October 2016. Observations from a suite of ground-based and remote sensing instruments between January 2000 and July 2017 were used to track progress of both rifts in unprecedented detail. Results reveal a steady accelerating trend in their width, in combination with alternating episodes of fast $\left(>600 \mathrm{mday}^{-1}\right.$ ) and slow propagation of the rift tip, controlled by the heterogeneous structure of the ice shelf. A numerical ice flow model and a simple propagation algorithm based on the stress distribution in the ice shelf were successfully used to hindcast the observed trajectories and to simulate future rift progression under different assumptions. Results show a high likelihood of ice loss at the McDonald Ice Rumples, the only pinning point of the ice shelf. The nascent iceberg calving and associated reduction in pinning of the Brunt Ice Shelf may provide a uniquely monitored natural experiment of ice shelf variability and provoke a deeper understanding of similar processes elsewhere in Antarctica.
\end{abstract}

\section{Introduction}

The Brunt Ice Shelf (BIS) is located along the Caird Coast at the eastern edge of Coats Land in East Antarctica, shown in Fig. 1. It is a dynamic environment, characterized by alternating decades of fast and slow flow (Thomas, 1973; Simmons and Rouse, 1984a, b; Simmons, 1986; Gudmundsson et al., 2017) and a number of large rifts that penetrate the full thickness of the ice shelf and stretch deep into its interior (Ander- son et al., 2014). These rifts are indicators of historical and recent glaciological activity and are long-lived features that form as the ice shelf goes through phases of steady growth followed by rapid ice loss through calving. Observational evidence for the episodic changes in ice shelf configuration has been obtained from a unique 57-year velocity record measured at several Halley Research Stations that have occupied locations on the BIS since 1956 (Gudmundsson et al., 2017) and from regular shipborne and satellite-derived outlines of the ice front dating back to 1915 (Anderson et al., 2014).

Using an ice dynamics model to investigate the relationship between flow velocities and ice shelf geometry, Gudmundsson et al. (2017) concluded that the observed changes in velocities can be explained by a calving-induced (un)pinning of the ice shelf at the McDonald Ice Rumples (MIR; Fig. 1). The MIR are a small grounded area in the northeastern corner of the BIS where the bottom of the ice shelf makes contact with a local rise in the seafloor bathymetry, and the resulting friction exerts a buttressing force on the remainder of the ice shelf. This is the only known pinning point on the BIS and the much larger neighbouring Stancomb-Wills Glacier Tongue, which at present cover a combined area of about $33000 \mathrm{~km}^{2}$.

Following the most recent calving event of the BIS in the early 1970s (Thomas, 1973), satellite images and aerial photography suggested that a significant part of the ice shelf in contact with the bedrock at the MIR was lost, which resulted in a loss of buttressing and a 2-fold increase in flow velocities between the late 1960s and the 1980s (Simmons and Rouse, 1984a). For illustrative purposes, the location of the ice front shortly after the calving event in the 1970s is 


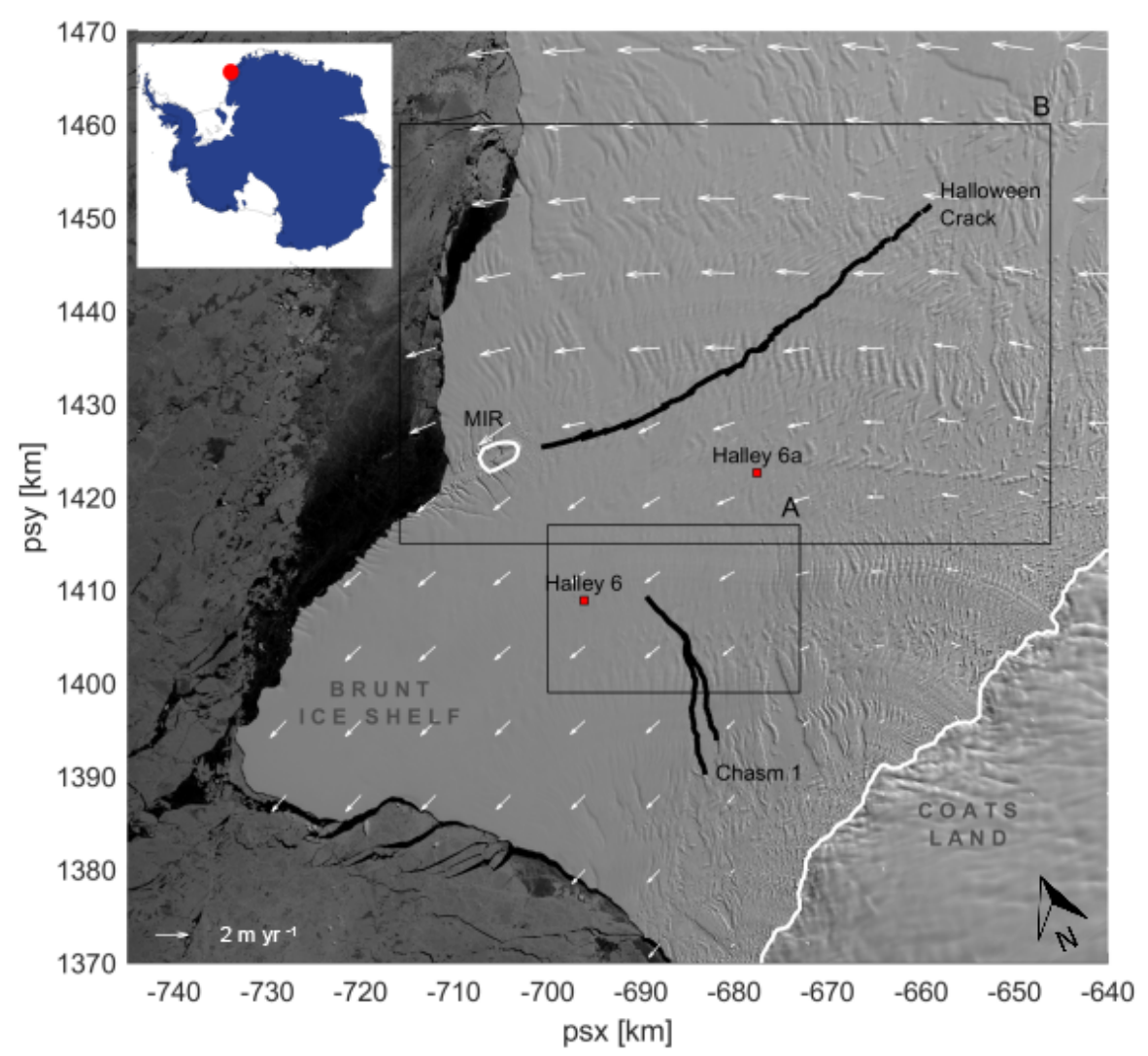

Figure 1. The Brunt Ice Shelf covers a $6500 \mathrm{~km}^{2}$ area along the Coats Land coastline in East Antarctica (see inset). The grounding line from the SCAR Antarctic Digital Database 6.0 (ADD; www.add.scar.org) is delineated in white and marks the boundary between the ice shelf and the adjacent continent, as well as a small pinning point at the McDonald Ice Rumples (MIR), which is absent in the ADD. The background image is a subset of a Landsat 8 scene (panchromatic band) from 15 March 2017, which was used to outline the present-day active rifts, Chasm 1 and Halloween Crack, which are highlighted in black. The flow of the ice shelf is illustrated by white arrows, sampled on a regular $8 \mathrm{~km}$ by $8 \mathrm{~km}$ grid. Red dots indicate the location of the Halley 6 Research Station (operational since 2012) and its new location at Halley 6 a (since February 2017). The black boxes indicate the geographical extent of Figs. 2a (A) and 3 (B).

shown in Fig. 8b. In subsequent decades, the BIS gradually readvanced and reestablished contact with the bedrock at the MIR, whilst velocities decreased to pre-1970 levels (Gudmundsson et al., 2017). This cycle of internal dynamical change controlled by calving-induced unpinning and subsequent regrounding at the MIR is arguably not a unique phenomenon, as many ice shelves around Antarctica, and in particular in Dronning Maud Land, are controlled by the presence of one or several pinning points (Matsuoka et al., 2015; Fürst et al., 2015; Favier et al., 2016; Berger et al., 2016). However, the long observational record and the relatively short calving frequency on the order of decades makes the BIS an ideal location to study this cycle.

Episodic observations of the configuration of the BIS since 1915 and effectively continuous observations since the 1990s suggest that, at present, the ice front is in its most advanced position since the start of measurements, and Anderson et al. (2014) hypothesized that a new calving cycle is likely to happen before 2020. In agreement with this prediction, a number of recent events have provided strong evidence for an immi- nent calving, in particular the growth of an old rift that has remained unchanged since the 1970s (Chasm 1 in Fig. 1) and the rapid formation and propagation of a new rift close to the MIR in austral summer 2016 (Halloween Crack in Fig. 1). In concurrence with these changes, Gudmundsson et al. (2017) reported on a new phase of ice-shelf-wide acceleration as surface velocities have increased by up to $10 \%$ per year since 2012. Detailed measurements of these changes have been facilitated by the presence of the Halley 6 Research Station, now located at Halley 6a (see Fig. 1) and an intensive monitoring programme that has been put in place to collect important glaciological data to help understand the dynamics of the BIS as it changes. In this study, we present the most recent findings of this programme, based on a suite of ground-based and remote sensing observations between 2000 and 2017. In particular, we report on the recent lengthening and widening of Chasm 1 since 2012 and the formation of Halloween Crack (HC) in October 2016 and provide some of the most detailed and complete observations of Antarctic rifts to date. 

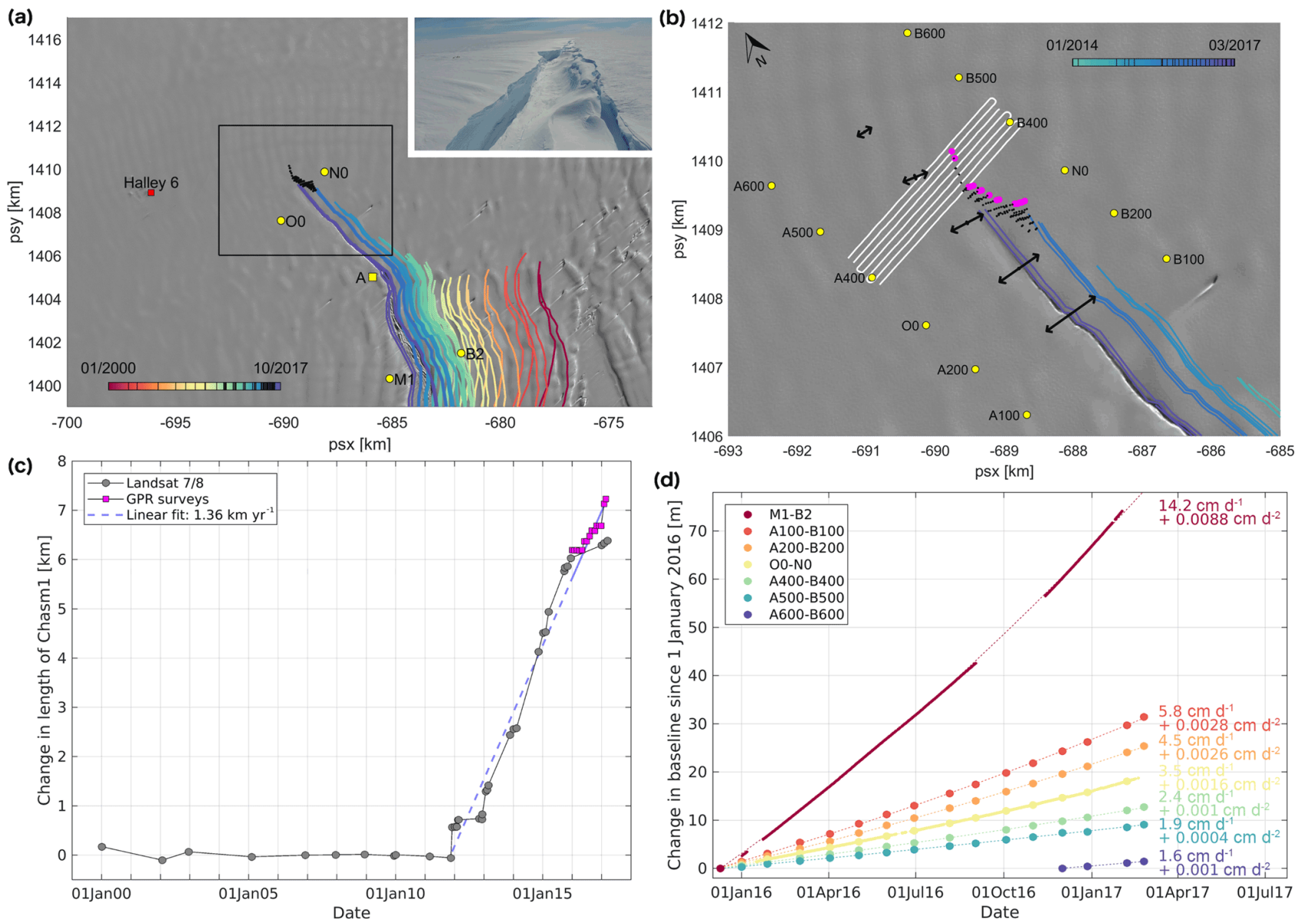

Figure 2. (a) Historical outlines of Chasm 1 from 6 January 2000 (red) to 15 March 2017 (purple), as the rift got advected by the ice flow. Outlines were obtained from a sequence of Landsat 7 and Landsat 8 panchromatic images, with acquisition dates as indicated by the black ticks in the colour bar. The background image is a subset of a Landsat 8 scene from 15 March 2017. The red dot indicates the location of Halley 6 research station, yellow dots are the locations of four permanent dual-frequency GPS stations, and the black box outlines the extent of (b). The inset in the top right shows an aerial image of Chasm 1 taken in December 2015, looking from the reference point A towards the crack tip. (b) Detailed overview of the area around the tip of Chasm 1, showing the local snow stake network (yellow dots), an example of the GPR survey lines (white lines), and progression of the crack tip as obtained from satellite (blue-to-purple outlines) and GPR data (black dots). Strain rosettes were obtained from the relative movement of the snow stakes; they capture the widening of Chasm 1 as well as local strain rates in the ice shelf. (c) Propagation of the tip of Chasm 1 with respect to its historical location prior to the reactivation in December 2012, based on Landsat 7/8 images (grey markers) and monthly GPR surveys (magenta markers). A linear fit through all data points shows an average lengthening rate of the rift of $1.36 \mathrm{~km} \mathrm{yr}^{-1}$. (d) Baseline distance across Chasm 1 as a function of time, measured by two pairs of permanent GPS stations $\left(O 0-N 0\right.$ and $M 1-B 2$ in a) and five pairs of snow stakes $\left(A_{i}-B_{i}\right.$, with $i \in\{100,200,400,500,600\}$ in $\left.\mathbf{b}\right)$. The least-squares quadratic fit is plotted as a dashed line.

As both rifts are a potential precursor to iceberg calving and future widespread changes to the dynamics of the BIS, sustained monitoring and a deeper understanding of these changes is of great relevance for many other ice shelves in Antarctica. Since iceberg formation is an important and often dominant component of their mass balance (Depoorter et al., 2013), and the weakening and total loss of ice shelves around the margins of the Antarctic Peninsula and the West Antarctic Ice Sheet have led to widespread dynamic changes to the mass balance of the ice sheet (Pritchard et al., 2012), lessons learned about the physical processes that control the dynamics of the BIS are directly transferrable to these ice shelves. Moreover, the wealth of observational data gathered on Chasm 1 and the $\mathrm{HC}$ provides a unique opportunity to advance and validate numerical models of fracture propagation and improve the treatment of iceberg calving laws in such models.

As a first step towards this goal, a simple but successful algorithm to simulate the propagation direction of fractures was used in conjunction with a finite-element ice flow model of the BIS. Model predictions were successfully tested against observations and used to estimate the future trajec- 
tory of both Chasm 1 and $\mathrm{HC}$, assuming continued propagation. This will ultimately allow us to predict future changes in ice shelf extent and investigate resulting dynamic changes to the flow, along lines similar to previous studies (Khazendar et al., 2009; Larour et al., 2014; Gudmundsson et al., 2017). We do not intend to address the more complex issues of fracture initialization and the propagation speed of existing rifts but rather present a heuristic algorithm for calculating rift trajectories once an initial fracture has formed.

In Sects. 2 and 3, a comprehensive overview of the growth of Chasm 1 and HC is presented, based on data from a network of permanent GPS stations and strain stakes, extensive over-snow radar surveys, panchromatic Landsat 7/8 and Sentinel-2 satellite images and novel methods using Sentinel-1A/B radar data. Some of the data are subsequently used in Sect. 4 to configure an ice flow model of the ice shelf and to perform a series of fracture propagation experiments that test our methods and provide a prediction for future propagation of both rifts. A discussion of the most important results in relation to the existing literature is provided in Sect. 5 and conclusions are given in Sect. 6.

\section{Recent reactivation of Chasm 1}

Chasm 1 is a $22 \mathrm{~km}$ long and, in some places, up to $2 \mathrm{~km}$ wide rift structure that cuts through the middle of the BIS from the southwest to the northeast. The rift originated at the grounding line in the 1970s, where the ice shelf is only weakly connected to the continent, and was advected by the ice flow to its present-day location depicted in Fig. 1. The formation of the rift coincided with a period of accelerating ice flow, which started in the 1970s (Gudmundsson et al., 2017) and was likely related to wide-spread dynamical changes to the ice shelf triggered by a calving event to the north of the MIR (Thomas, 1973). After an initial phase of widening and growth, early satellite images showed that the location of the northernmost tip of Chasm 1 has remained unchanged with respect to the surrounding ice shelf since at least February 1980. Since the start of the Landsat 7 and 8 era in the early 2000s, the summer extent of Chasm 1 has been tracked more reliably and at regular intervals using all available cloud-free panchromatic images, resulting in a time series of 35 manual outlines presented in Fig. 2a. Up until late 2012, the rift showed little change to its overall shape and extent. However in November 2012, after more than 3 decades of inactivity, the tip of Chasm 1 started to propagate along a linear trajectory towards the MIR in the north, covering a total distance of about $7.3 \mathrm{~km}$ in 5 years.

\subsection{Propagation of the Chasm 1 rift tip}

In order to track temporal changes to the length of Chasm 1 , the distance between the crack tip and a fixed reference point on the ice shelf has been calculated. The reference point is indicated by A in Fig. 2a and corresponds to a persistent surface feature that gets advected with the flow, known as a deflation hollow (Konovalov, 1964; Thomas, 1973). It is visible in all the satellite images used. The propagation of Chasm 1 is approximated by the straight-line distance between $\mathrm{A}$ and the tip of the rift as estimated from the outlines in Fig. 2a. Results for this analysis are shown in Fig. 2c and point towards a near-linear growth between late 2012 and early 2017, with two episodes of significant slowdown in 2012 and 2016.

The accuracy of these results is limited by our inability to detect potential sub-surface propagation of the rifts, the variability in image contrast due to solar azimuth and zenith angles and the resolution of the panchromatic images $(15 \mathrm{~m})$, which prevents the reliable detection of fine surface cracks less than a pixel wide. It is also impossible to track progress during the austral winter months (AprilSeptember) when visible images are unavailable. In order to address these issues and improve the accuracy of the location of the rift tip, ground penetrating radar (GPR) measurements were acquired once every month from January 2016 to February 2017. Surveys were carried out using a radar unit with $400 \mathrm{MHz}$ antenna from Geophysical Survey Systems, Inc., set to operate at a depth range of $30 \mathrm{~m}$ and tied to a dual-frequency GPS to guarantee accurate geolocation of the radar traces. During each survey, a series of parallel lines was acquired to cover the area around the rift tip, with a spatial separation of $100 \mathrm{~m}$ and directed approximately perpendicular to the propagation direction of the rift. An example of such a set of survey lines for 24 February 2017 is shown by the white lines in Fig. $2 b$.

The GPR data were detrended and a divergence compensation scheme was applied to enhance the intensity of the deeper layers, using the post-processing software package ReflexW from Sandmeier Geophysical Research. The processed data were used to detect narrow cracks less than $1 \mathrm{~m}$ wide, both at the surface and at depth, allowing to determine the exact extent of Chasm 1 much more precisely and at regular time intervals both in summer and throughout the winter. The black dots in Fig. 2 b represent all locations where cracks were detected within the vertical range of the GPR, for a total of 15 monthly acquisitions between 1 January 2016 and 24 February 2017.

In general, the tip of Chasm 1 is not uniquely defined but consists of a number of parallel branches at a spacing of several hundred metres, approximately aligned with the overall propagation direction. This non-simple structure of the rift tip is particularly evident between 1 January 2016 and 1 January 2017 during a phase of reduced rift tip propagation and is illustrated in Fig. 3 using data from a GPR survey carried out on 4 May 2016. Figure 3a shows the GPR track in white, overlying a Landsat 8 image that predates the survey by about 2 months. Two radar profiles along sections $\mathrm{A}$ and $\mathrm{B}$ in Fig. 3a are shown in Fig. 3b and c, allowing the identification of two fractures along section A and three fractures along section $\mathrm{B}$, marked by vertical black stripes. A detailed 
(a)

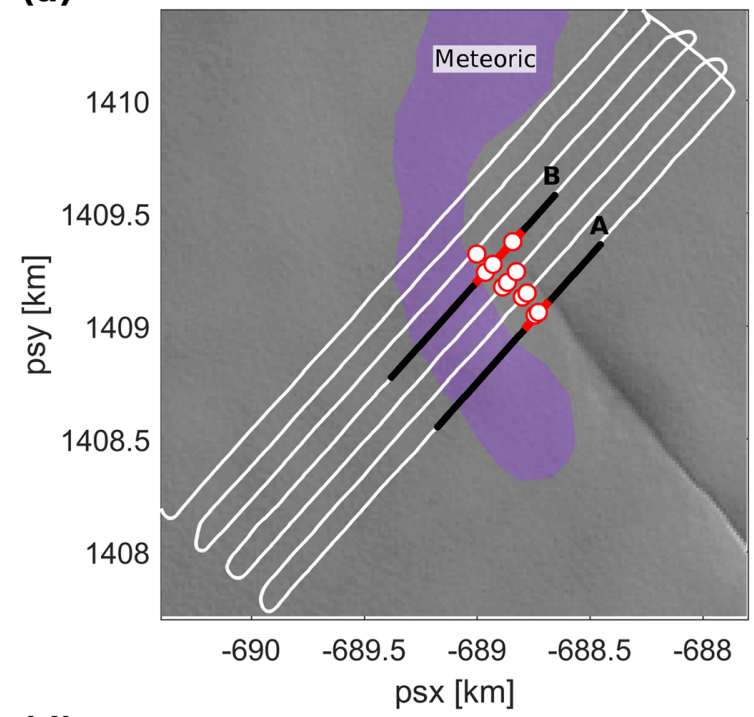

(d)

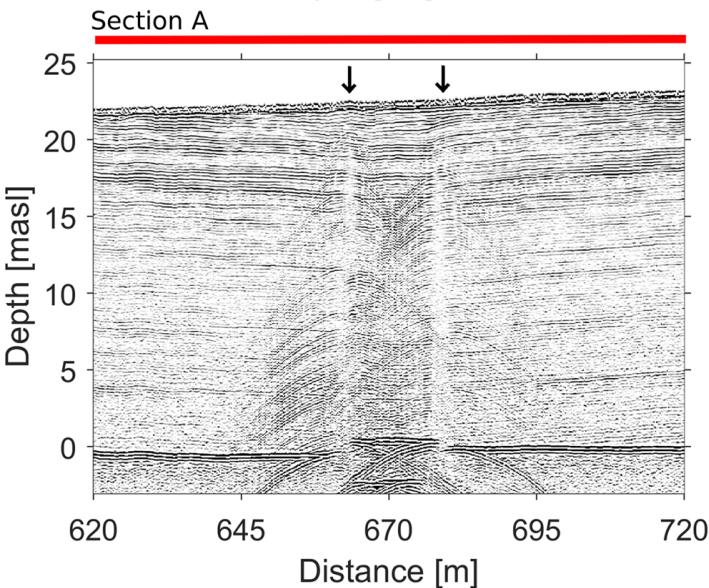

(b)

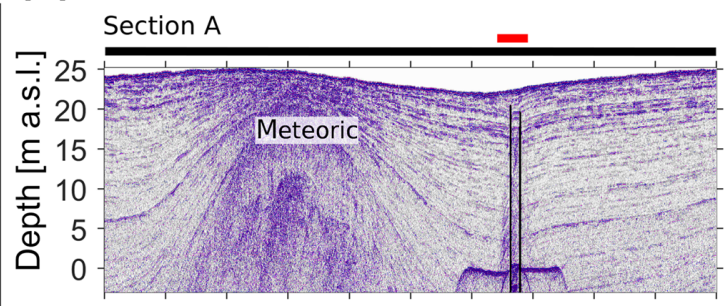

(c) Section $B$

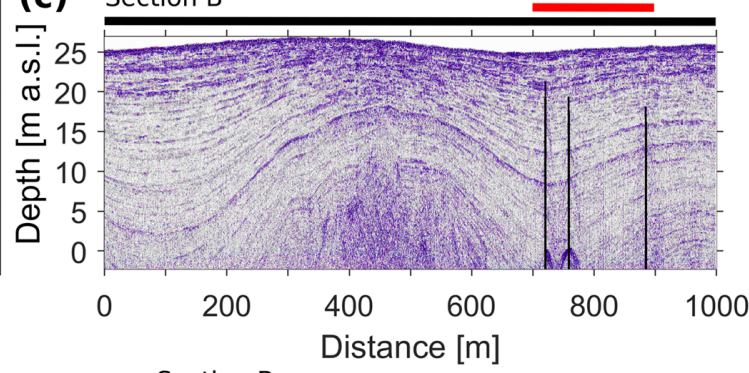

(e) Section B

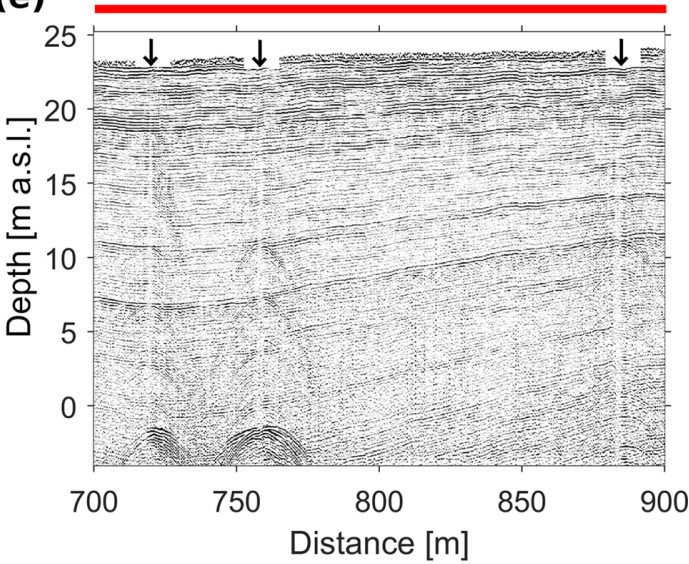

Figure 3. (a) GPS track of a GPR survey carried out on 4 May 2016 (white line), overlying a Landsat 8 image from 3 March 2016. Red dots correspond to locations where a fracture has been observed in the GPR data. Black line segments A and B correspond to the location of the radar sections displayed in panels (b) and (c), respectively. The purple shading outlines the location of a large structure of meteoric ice embedded within the ice shelf (b) Radar section along line segment A in panel (a). Vertical black lines indicate the location of fractures in the ice shelf. (c) Similar to panel (b) but for line segment B. (d) A detailed view of the fractures along section A. The spatial extent is indicated by the red line above panel (b) and vertical arrows locate the radar signature of each fracture. (e) Similar to panel (d) but for section B.

view of these fractures is shown in Fig. 3d and e. All branches of the rift follow the edge of a large structure within the ice, marked by "meteoric". The full spatial extent of this feature is shown in Fig. 3a and has been identified as a block of meteoric ice that originated at the grounding line and got embedded within the firn pack. This is not a unique feature and similar structures of variable size and orientation have been observed from GPR surveys all across the ice shelf (King et al., 2018). It is very likely that such large-scale and wide-spread irregularities in ice properties are responsible for a significant dispersion of the crack tip growth. As the tip of Chasm 1 continued to propagate, some branches eventually became inactive, whereas others continued to grow. From January 2017 onwards, only one branch was apparent near the tip.
For each monthly GPR survey, the tip of the most advanced branch of Chasm 1 is highlighted in magenta in Fig. 2b, and the corresponding extent of the rift is represented by magenta markers in Fig. 2c. A comparison between the GPR data and Landsat-derived results in Fig. 2c shows that the latter systematically underestimate the extent of Chasm 1 by up to a kilometre. Not only are satellite data resolution limited, but GPR data also show that the tip of the rift tends to be further advanced at depth, and only becomes detectable at the surface at a later stage. In agreement with the satellite data, GPR measurements show a deceleration in the propagation between January 2016 and early 2017. However, a subsequent surge of the crack tip in January and February 2017 was only captured by the GPR data, and satellite data alone 
would have led to the erroneous conclusion that Chasm 1 has stagnated until propagation once again became apparent.

\subsection{Widening of Chasm 1}

The gradual lengthening of Chasm 1 in the horizontal plane is caused by tensile stresses normal to the fracture plane. After fracture initialization, such stresses tend to widen the rift at a rate which a priori depends on the far-field stresses and on material properties local to the fracture tip. The precise nature of this relationship cannot be determined due to a lack of observational data. However, for Chasm 1 a network of snow stakes and permanent GPS stations was installed to monitor rift widening rates at regular intervals. The network is shown in Fig. $2 \mathrm{~b}$ and consists of six stakes (yellow markers) at $1 \mathrm{~km}$ separation on each side of Chasm 1, named $A 100-A 600$ on the west and $B 100-B 600$ on the east side. The relative location of all stakes was measured once a month between December 2015 and February 2017, using a GPS base station at $A 600$ and roving stations at all other stakes. Two stakes, $O 0$ and $N 0$, were occupied permanently and have provided a daily measurement of their location since January 2016. A further pair of permanent GPS stations, named $M 1$ and $B 2$ in Fig. 2a, was installed in May 2015 and has provided additional baseline measurements across Chasm 1 further to the south and away from the tip. By combining these data, the widening of Chasm 1 has been measured along seven different baselines, some across the historical extent of the crack (M1-B2), others across the recently formed branch (A100$B 100, A 200-B 200, O 0-N 0, A 400-B 400$ ), and some ahead of the current crack tip ( $A 500-B 500, A 600-B 600$ ).

All data were post-processed using the advanced baseline analysis tool within the Infinity software package from Leica Geosystems, and a summary of the results from 1 December 2016 until 27 February 2017 is shown in Fig. 2d. All baselines get longer over time, ranging from less than $2 \mathrm{~cm} \mathrm{day}^{-1}$ ahead of the rift tip to $2.4 \mathrm{~cm} \mathrm{day}^{-1}$ between $A 400$ and $B 400$ and $14.2 \mathrm{~cm} \mathrm{day}^{-1}$ between $M 1$ and $B 2$. Part of the lengthening can be attributed to the background spreading of the ice shelf, as is apparent along $A 500-B 500$ and $A 600-B 600$ where the crack has not yet propagated, whereas the remainder of the extension is due to widening of the rift.

Further details about the propagation behaviour of Chasm 1 can be obtained from a full strain rate analysis of the stake network. Strain rosettes in Fig. $2 b$ show the principal strain rate directions and magnitudes, as computed for five different squares within the network. Note that towards the south of the $A 500-B 500$ line, these results also incorporate widening (Mode I) and shear (Mode II) of the rift, and they are therefore not material strain rates in the strictest sense. The first principal components are extensive, confirming earlier results from the baseline analysis. They are oriented perpendicular to the rift trajectory, indicating minimal shear along the rift and hence a negligible Mode II compo- nent. The second principal components are also extensive, but about 2 orders of magnitude smaller.

The strain rates show an increasing trend away from the rift tip, and have a non-negligible second-order component in time, which indicates that Chasm 1 is widening at an accelerating rate. Unlike the spatial propagation of the tip location, the widening of Chasm 1 happens evenly and without significant deviations from the trend line. For example, the transition from a period of slow crack propagation to a rapid change in the location of the crack tip in early 2017 (Fig. 2c) is not obviously reflected in the widening rates (Fig. 2d). This suggests that the widening is dominated by the slowly varying far-field stresses, and is uncorrelated to the rift tip propagation, which is sensitive to spatially variable properties of the ice shelf local to the tip, such as the ice viscosity and ice thickness. Similar observations have previously been made by (Joughin and MacAyeal, 2005) for two rifts that led to the calving of tabular icebergs from the Ross Ice Shelf, Antarctica, and we will come back to this result in Sect. 5 .

\section{Halloween Crack formation and propagation}

On 31 October 2016, airborne observations revealed a new rift in the BIS, extending from the MIR towards the east over a distance of about $15 \mathrm{~km}$. The earliest evidence for this fracture, named Halloween Crack, dates back to a Landsat 8 image from 11 October 2016, whereas an earlier image from 29 September 2016 only revealed a number of disconnected segments extending over a combined length of $2 \mathrm{~km}$. A later outline from 15 March 2017 is shown in Fig. 1 and illustrates the extent of the $\mathrm{HC}$ at the onset of austral winter. By that time, the crack had grown an additional $35 \mathrm{~km}$ in length and cut across the BIS along a west-east trajectory, roughly parallel to the grounding line, and at a $90^{\circ}$ angle to Chasm 1 . This rapid growth has been tracked at frequent intervals using Landsat 8 and Sentinel-2 panchromatic images, and a total of 30 manual outlines were acquired between 1 January 2016 and 15 March 2017. The resulting time series is shown in Fig. 4 with colours indicating the corresponding acquisition date.

\subsection{Propagation of the tip of Halloween Crack}

The HC originated about $15 \mathrm{~km}$ east of the MIR, and its tip propagated rapidly in opposite directions. From November 2016 onwards, growth stagnated in the west as the rift approached the MIR but continued at an unabated rate towards the east. When plotted as a function of time (see blue dots in Fig. 5a), the total length of the HC increased by $34.2 \mathrm{~km}$ over 158 days, or an average of $216 \mathrm{mday}^{-1}$, subject to observational errors related to our inability to detect subsurface or narrow surface cracks using visible satellite images, as discussed in Sect. 2.1. Discarding such uncertainties, it is clear that the propagation rate has been highly variable in time, 


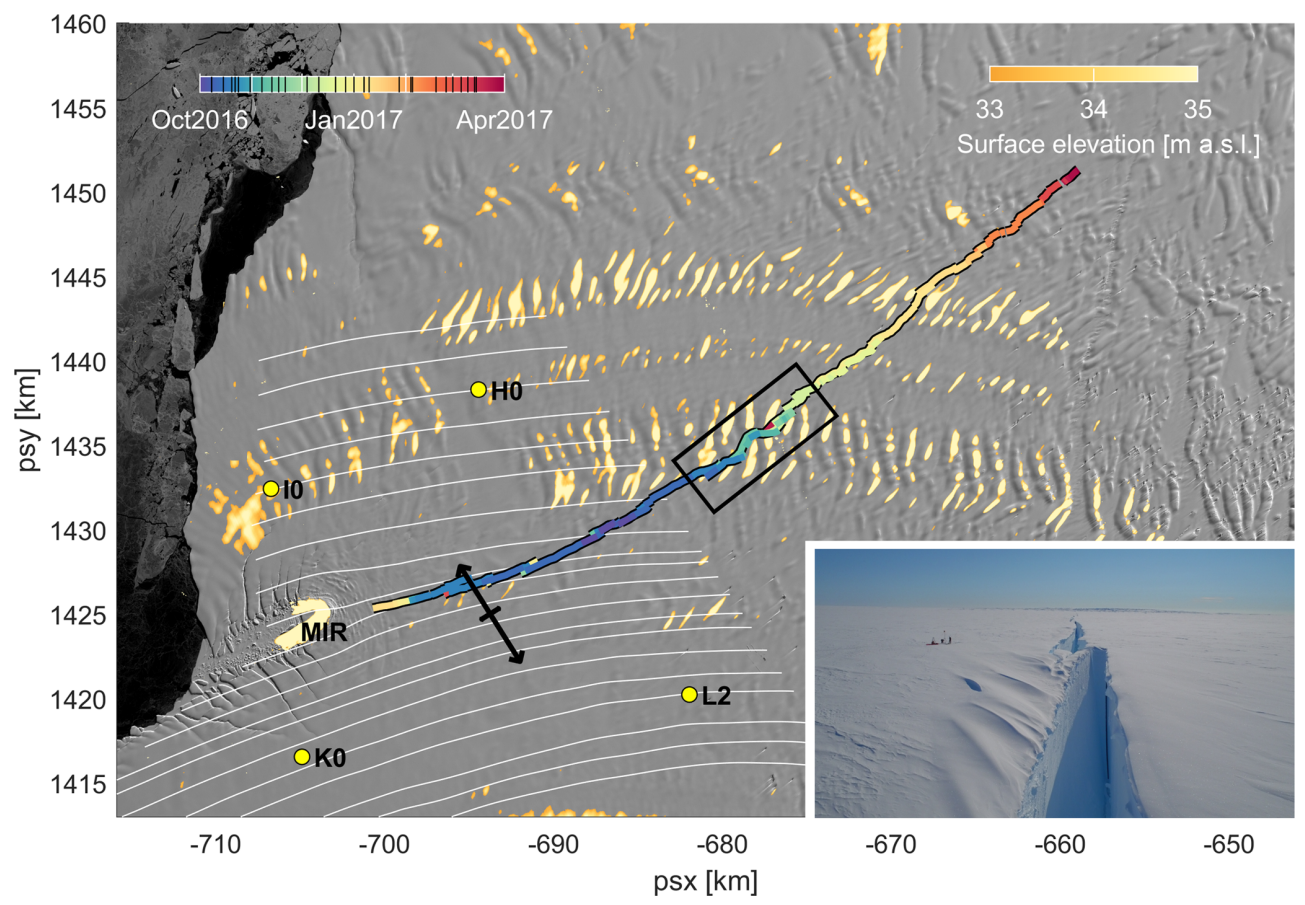

Figure 4. Extent of Halloween Crack (HC) based on a time series of manual outlines from Landsat 8 and Sentinel-2 images; the corresponding dates are indicated by black ticks in the colour bar. The background image is a Landsat 8 scene from 15 March 2017, the yellow dots correspond to the location of four permanent GPS stations $(K 0, I 0, H 0$ and $L 2)$, and the inset in the lower right shows an aerial image of the HC taken in January 2017 from a location $5 \mathrm{~km}$ to the east of the MIR. Orange-to-yellow colours highlight areas with a surface elevation above $33 \mathrm{~m}$, and the black box outlines an area where the HC cuts through a band of thicker ice. White lines are flow lines based on a velocity field from 2015, prior to the formation of the HC, and indicate a localized divergence of flow around the MIR. The strain rosette is calculated from the differential motion of $L 2, K 0$ and $H 0$ between 3 October 2016 and 1 February 2017.

with very little, if any, propagation in early November 2016 and periods during January, February and March 2017 yet more than $600 \mathrm{~m} \mathrm{day}^{-1}$ during intervening periods.

This variability has also been observed for Chasm 1 and is at least partly related to the heterogeneous structure of the ice shelf. As the tip of the rift propagates, it encounters areas with higher (lower) fracture toughness, which requires a higher (lower) energy to break through, and leads to a slowdown (speedup) of the propagation. In the case of the $\mathrm{HC}$, a period of slow propagation from mid-October to mid-November 2016 occurred when the rift tip encountered successive bands of thicker meteoric ice, apparent in the surface topography in Fig. 4 and outlined by the black box. These blocks of ice are of the same origin as the meteoric ice structure near the tip of Chasm 1, as discussed in Fig. 3. The blocks originate at the grounding line, where the grounded ice calved at regular intervals leaving spaces between icebergs that were gradually filled by sea ice, marine ice and surface accumulation (King et al., 2018). As the heterogeneities and the direction of rift propagation were misaligned by about $70^{\circ}$, the $\mathrm{HC}$ changed direction as it followed a staircase-like trajectory with successive phases of propagation along and perpendicular to the icebergs. This caused temporary changes in its alignment with respect to the large-scale stress field, which might explain part of the slowdown. Other studies have suggested that the presence of marine ice can suppress the speed at which rifts propagate, and several ice shelves such as Larsen $\mathrm{C}$ and Filchner-Ronne ice shelves contain rifts that terminate in marine ice-rich suture zones (Glasser et al., 2009; Hulbe et al., 2010; McGrath et al., 2012; Jansen et al., 2013; Borstad et al., 2017). However, very few studies have investigated the relationship between rift tip propagation and fracture toughness of ice directly (see for example Rist et al., 2002) and the dynamics of rift tip propagation remains subject to large uncertainties.

\subsection{Widening of Halloween Crack}

The sudden fracture of the ice shelf and the abrupt formation of the HC suggests a period of critical crack growth, which typically occurs in materials that are subjected to high tensile stresses or stresses that are applied for long enough such that initial fractures grow to a critical length, after which catastrophic failure happens (Lawn, 1993; Rist et al., 2002). Satellite images from 2014 and 2015 show early indications of small segmented fractures at the surface in the area where the $\mathrm{HC}$ subsequently originated, and it is feasible that in October 2016 these segments reached a critical length, which 

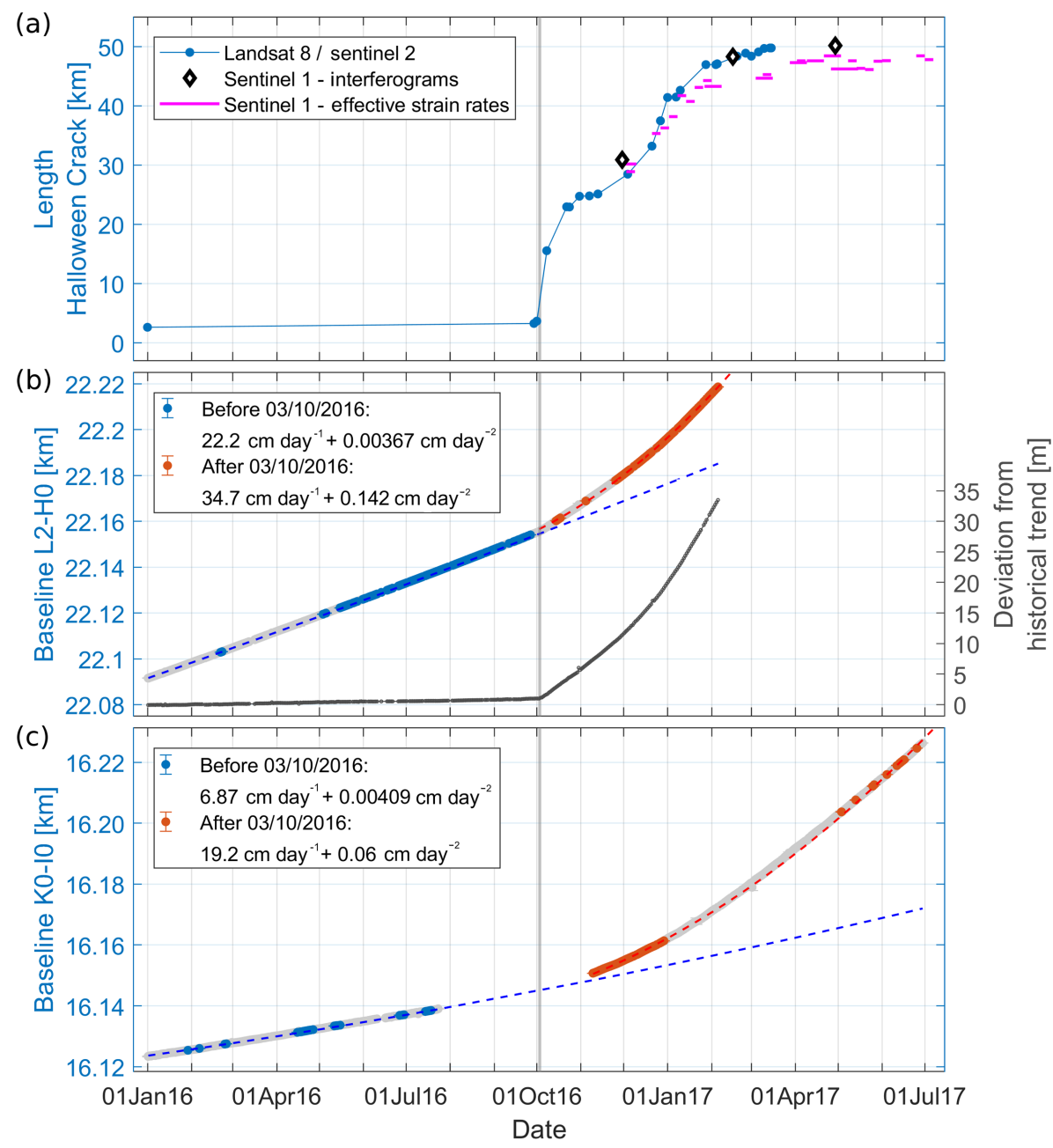

Figure 5. (a) The blue curve represents the length of Halloween Crack (HC) as a function of time based on a sequence of outlines from visible Landsat 8 and Sentinel-2 images. Black diamonds indicate the length of the HC based on manual tracking of the rift tip in a sequence of

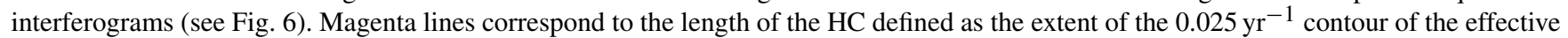
strain rate, derived from Sentinel-1A/B velocity fields (see Fig. 7b). (b) Left axis: widening of the HC along baseline $L 2-H 0$ in Fig. 4; right axis (black line): deviation from the historical trend prior to the formation of the HC on 3 October 2016. (c) Same as panel (b) but for GPS stations $K 0$ and $I 0$. The grey vertical line in each image highlights the period around 3 October 2016, when the HC was formed.

led to the rapid formation of the HC. During this short phase of critical growth, the rift propagation might have reached a considerable fraction of the speed of sound, and continued until changes in the remote stress field stabilized the crack and a quasi-static regime with slower growth rates was reestablished.

Once failure occurred, the ice adjacent to the free surfaces of the rift became fully unloaded, and the strain was entirely converted into opening of the rift. The transition from a loaded to an unloaded state of the ice shelf was measured using a network of four permanent GPS stations positioned on both sides of the HC trajectory. As shown in Fig. 4, stations $K 0$ and $L 2$ were located south of the HC, and stations $I 0$ and $H 0$ were positioned towards the north, forming two independent baselines across the rift: $K 0-I 0$ and $L 2-H 0$.
Daily values for the length of each baseline were obtained using the baseline processing toolbox in Leica Infinity, and results are presented in Fig. 5b ( $L 2-H 0)$ and Fig. $5 \mathrm{c}(\mathrm{KO}-$ I0). Phase-fixed solutions with a precision of about $1 \mathrm{~mm}$ were obtained for $45 \%$ of the measurements despite the length of the baselines ( 16 and $22 \mathrm{~km}$ ) and are highlighted in blue and red in Fig. 5b and c. The remaining float solutions have a precision on the order of $5 \mathrm{~cm}$ and are coloured in grey. Although all stations were installed prior to 2013, only data after 1 January 2016 were used in this study, providing 10 months of coverage leading up to the formation of the HC in early October 2016. Note that a failure at $I 0$ caused a gap in the $K 0-I 0$ baseline between August and November 2016, and the L2-H0 time series ended in February 2017, when station $L 2$ was removed. 


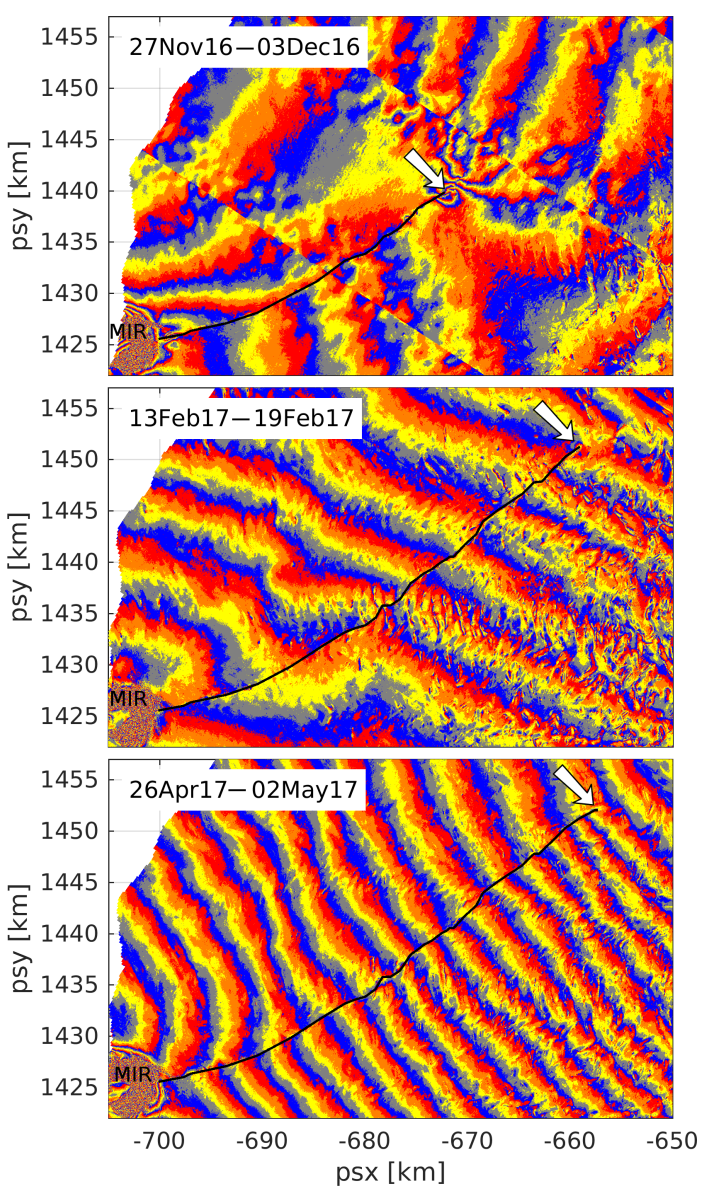

Figure 6. A selection of interferograms obtained about 2 months apart, showing the progress of Halloween Crack as it propagated from the McDonald Ice Rumples (MIR) towards the east. White arrows point towards the eastern tip of the crack.

Both baselines show a qualitatively similar behaviour over the measurement period, with a close-to-linear extension rate (dashed blue line in Fig. 5b and c) followed by a rapid deviation from the historical trend line and a significant acceleration. For the $L 2-H 0$ baseline, the transition happened abruptly on 3 October 2016, as indicated by the kink in the deviation from the historical trend, which is plotted on the right axis in Fig. 5b (black line). On that date, spreading rates along $L 2-H 0$ increased near-instantaneously from 22.2 to $34.7 \mathrm{~cm}$ day $^{-1}$ with an acceleration of $0.142 \mathrm{~cm} \mathrm{day}^{-2}$.

For the $K 0-I 0$ baseline, a gap in the data prevents precise dating of the transition, but extrapolation of the trend lines indicates early October as the most likely time of change. Although the stations are positioned on opposite sides of the MIR, an area of naturally diverging flow, it is unlikely that the large change in separation between $K 0$ and $I 0$ can be attributed to background flow dynamics during the 3-month period of missing data. From the 2015 flow lines in Fig. 4 (prior to the formation of the $\mathrm{HC}$ ) it is clear that the divergence of flow is localized around the MIR, and all GPS stations are located on continuously diverging paths without abrupt changes to their direction and speed that could explain the sudden acceleration in baseline distance.

Based on these observations we conclude that the sharp increase in extension rate between $L 2$ and $H 0$ on 3 October 2016 can be fully attributed to the formation, opening and shear displacement of the HC. Equally, the increased divergence between $K 0$ and $I 0$ in early October 2016 is attributed to the formation of the $\mathrm{HC}$ and indicates an increased separation between the north and south sides of the MIR. A full strain rate analysis of the differential movement between stations $L 2, K 0$ and $H 0$ between 3 October 2017 and 1 February 2017 shows that the principle strain rate directions are both extensive and oriented perpendicular and parallel to the HC. The corresponding strain rosette is shown in Fig. 4 and provides evidence for a pure Mode I loading of the rift.

In order to pinpoint the exact source for the increase in baseline extension after the formation of the HC, absolute locations of the GPS stations were obtained from a precise point positioning analysis using the Bernese GNSS software. Results indicate that the signal is caused by an acceleration of the surface velocities at $I 0$ and $H 0$ to the north of the $\mathrm{HC}$, following the physical separation of the northern and southern parts of the ice shelf. This signal has subsequently been confirmed by satellite-derived surface velocities, which show a clear discontinuity in surface velocities across the rift with higher velocities towards the north across its entire length, including the area downstream of the MIR. An example of such a velocity field for May 2017 is shown in Fig. 7a.

\subsection{Tracking of Halloween Crack using synthetic aperture radar (SAR) data}

Due to the fast propagation of the $\mathrm{HC}$ and the complexity of the terrain, it is unfeasible to carry out ground-based radar measurements to accurately track the location of the crack tip. In addition, satellite coverage of the ice shelf in the visible spectrum is lost during the austral winter months, so alternative methods need to be developed to provide year-round coverage of the propagation. Data from the Sentinel-1A/B satellites provide a viable alternative, as they carry an active C-band SAR instrument that is not affected by cloud cover or the absence of visible light.

A well-known method to study fracture propagation using SAR data exploits the phase difference between two images taken several days apart and is known as interferometric SAR or InSAR. This method is routinely used in earth surface deformation monitoring (see e.g. Bürgmann et al., 2000, for a review), ice flow monitoring (see e.g. Goldstein et al., 1993, for one of the earliest examples) and grounding line tracking. Its application to ice shelf rift deformation has been limited (see e.g. Larour et al., 2004a) although there has been a renewed interest in the method due to the improved spatial and temporal coverage of SAR data for Antarctica's ice shelves. 

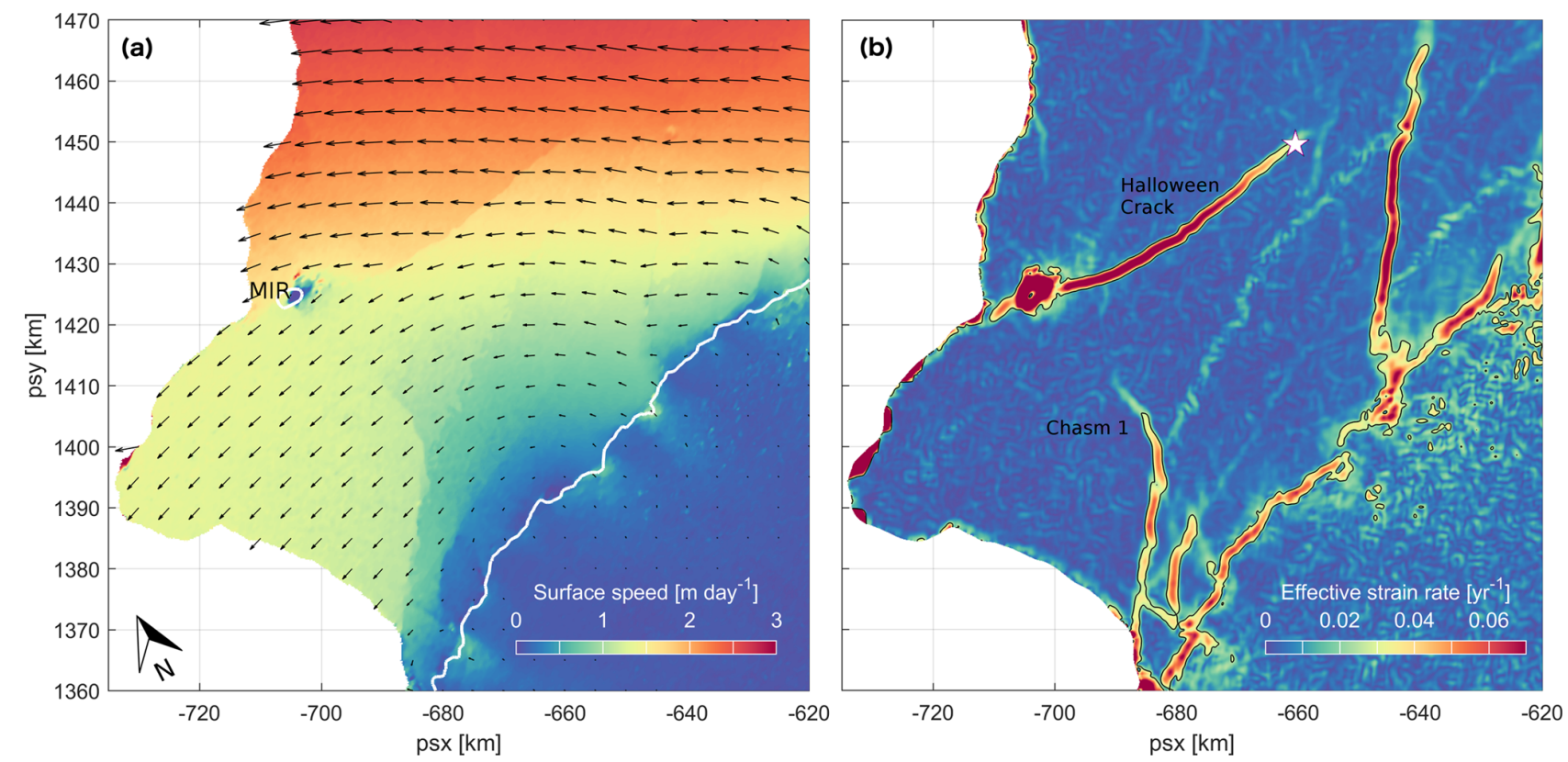

Figure 7. (a) Surface velocities subsampled onto a $4 \mathrm{~km}$ by $4 \mathrm{~km}$ regular grid (arrows) and speed (colours), obtained from a Sentinel-1 image pair (14 and 20 May 2017) using an iterative offset tracking method. (b) Effective strain rates derived from the velocity field in panel (a) using a quadratic regression method as detailed in the main text. The black line corresponds to the $\epsilon_{\mathrm{e}}=0.025 \mathrm{yr}^{-1} \mathrm{contour}$ and the white star indicates the easternmost extent of the $\mathrm{HC}$ as outlined by the contour.

Discontinuities in the differential phase (or interferogram) typically correspond to areas of anomalously high surface deformation, which can be traced manually and associated with active fracture zones. The technique is demonstrated in Fig. 6, which shows three interferograms for the area around HC separated by about 2 months. In each image a discontinuity in the interferometric fringes marks the trajectory of the rift as it propagates from the MIR towards the east. Black diamond markers in Fig. 5a specify the length of each outline, and a good agreement is found between SAR-derived estimates of the rift length and earlier results obtained from visible satellite images.

Despite the success of this technique, interferograms are often difficult to interpret, especially in places with a complex surface topography such as the BIS, and phase discontinuities caused by artefacts in the data are easily mistaken for physical signals. The method is also less appropriate for slowly propagating rifts with surface deformations that are too small to detect over the 6-day repeat cycle, such as Chasm 1. To avoid these issues, a more quantitative and robust approach to monitor fracture deformation is explored, based on SAR-derived velocity fields and the corresponding horizontal strain rates. As the dual satellite configuration of Sentinel-1A/B provides complete coverage of the BIS every 6 days, it is ideally suited for the frequent recovery of surface velocities using an iterative offset tracking method developed by Nagler et al. (2015). As an example, Fig. 7a shows the horizontal velocity field derived from two Sentinel-1 SAR images taken on 14 and 20 May 2017. The horizontal strain rate components $\dot{\epsilon}_{x x}, \dot{\epsilon}_{x y}$ and $\dot{\epsilon}_{y y}$ were calculated using a local quadratic regression of the velocity field over a $2 \mathrm{~km} \times 2 \mathrm{~km}$ square and used to obtain the effective strain rate $\dot{\epsilon}_{\mathrm{e}}=\sqrt{\left(\dot{\epsilon}_{x x}^{2}+2 \dot{\epsilon}_{x y}^{2}+\dot{\epsilon}_{y y}^{2}\right) / 2}$ shown in Fig. 7b. Again it should be noted that these values also incorporate widening (Mode I) and shearing (Mode II) of the rifts, and they are therefore not material strain rates in the strictest sense. Average values across the ice shelf are less than $0.01 \mathrm{yr}^{-1}$, whereas higher-than-average strain rates up to $0.1 \mathrm{yr}^{-1}$ are found in the vicinity of the MIR and along the $\mathrm{HC}$ and Chasm 1. Other areas with high strain rate are the grounding line and a shear margin, which extends from the grounding line at around $x=-645 \mathrm{~km}$ towards the northeast.

In order to define an objective measure for the extent of the $\mathrm{HC}$ based on strain rates, the $\dot{\epsilon}_{\mathrm{e}}=0.025 \mathrm{yr}^{-1}$ contour is used as an approximate outline of the rift, and the easternmost extent of the contour is used as a proxy for the location of the crack tip. From this location, indicated by the white star in Fig. 7b, the length of the HC can be calculated. This process removes biases related to the manual interpretation of images and has been applied to 22 velocity maps and corresponding effective strain rates, acquired by Sentinel-1A/B between November 2016 and July 2017. For each acquisition, the $\dot{\epsilon}_{\mathrm{e}}=0.025 \mathrm{yr}^{-1}$ contour was identified and used to track the extent of the HC. The results are shown by the magenta lines in Fig. 5a, where the horizontal limits of each line 
indicate the acquisition dates of the SAR image pair used to derive the velocity field.

The precision of our method to estimate the length of the rifts can be determined by comparing results for overlapping periods and shows a spread of around $2 \mathrm{~km}$. A comparison to manual tracking from visible images (Landsat 8, Sentinel2) shows that the two independent measurements are generally in good agreement, although there is a bias towards smaller values for the SAR-derived values. This is in part due to a systematic underestimation of the strain rates at the rift tip due to smoothing by the quadratic regression method, and in part because the $\dot{\epsilon}_{\mathrm{e}}=0.025 \mathrm{yr}^{-1}$ contour fails to capture the lower strain rates near the very tip of the rift. However, the record is internally consistent and, importantly, presents a reliable extension beyond previous summer measurements. It shows a sustained reduction in lengthening rate of the HC since February 2017, as the tip covered about $5 \mathrm{~km}$ or 32 m day $^{-1}$ between early February 2017 and mid-July 2017, compared to $366 \mathrm{~m} \mathrm{day}^{-1}$ during the first 4 months of propagation.

\section{Model predictions of rift propagation direction}

As the satellite-derived effective strain rates ahead of the tip of the HC and Chasm 1 in Fig. 7b are not significantly different from the average far-field strain rates across the ice shelf, they cannot be used as a direct indicator for future rift propagation. Moreover, effective strain rates derived from a Sentinel-1 velocity map in June 2015 (not shown) do not contain any evidence for the nascent formation of the $\mathrm{HC}$, indicating that they cannot be used with confidence to predict when and where rifts will form in the ice shelf. However, information in the directionality of the stress field can be used to estimate the trajectory of propagation once a rift has formed. Such methods range from sophisticated modern fracture mechanics including linear elasticity theory (Rist et al., 2002) to simple criteria based on the direction of maximum tensile stress (Ingraffea, 1987). As the first principal stress across the ice shelf is tensile, it indicates the direction perpendicular to which fractures are most likely to propagate. Here we present a simple approach to simulate the propagation direction of existing fractures based on the latter method and test our results against the observed trajectory of the HC.

\subsection{Model setup and fracture propagation algorithm}

In order to predict the propagation direction of existing fractures in the BIS based on the calculated stresses, surface velocities from Sentinel-1 and ice thickness data were assimilated in the SSA (shallow shelf approximation) flow model Úa (Gudmundsson et al., 2012). The boundaries of the model domain were chosen to coincide with the grounding line and ice front of the BIS and extended a further $150 \mathrm{~km}$ towards the east to include the neighbouring Stancomb-Wills Glacier
Tongue, in order to fully capture the spatial variability in strain rates and to allow a sufficiently large domain to propagate the existing rifts. A triangular mesh with linear elements was used, with the distance between nodes varying from $250 \mathrm{~m}$ for the BIS to $1 \mathrm{~km}$ elsewhere. The flow at the grounding line was prescribed by a Dirichlet condition, and Chasm 1 was represented as an ice-free area, i.e. a gap in the model domain.

Ice thickness values for the BIS were derived from a highresolution $(3 \mathrm{~m})$ WorldView surface digital elevation model acquired between 2012 and 2014, and values were binned onto a coarser $1 \mathrm{~km} \times 1 \mathrm{~km}$ grid. Elevations above the ellipsoid were translated into elevations above sea level using a tidal correction (Gudmundsson et al., 2017) and a EIGEN6C geoid correction and converted into ice thickness values assuming floatation and a two-layer density model with a constant $30 \mathrm{~m}$ firn column $\left(750 \mathrm{~kg} \mathrm{~m}^{-1}\right)$ overlaying pure ice $\left(920 \mathrm{~kg} \mathrm{~m}^{-3}\right)$. For the Stancomb-Wills Glacier Tongue a subset of the Antarctica-wide ice shelf thickness dataset by Chuter and Bamber (2015) was used.

The mismatch between observed and modelled surface velocities was minimized through an iterative optimization (or inversion) of the rate factor in Glen's flow law with exponent $n=3$. A Tikhonov regularization was used and the regularization multiplier, $\lambda_{\text {AGlen }}=10^{3}$, was determined through a L-curve approach to optimize the misfit and avoid overfitting. In areas away from the grounding line and the immediate vicinity of the MIR, the solution converged towards observed values of the surface velocities within 100 iterations, and the inversion was ended after 200 iterations. The resulting stress field was used to calculate the fracture trajectories as follows.

Each rift was seeded at a predefined location in the model, informed by the observed location of an initial fracture or the tip of an existing rift in the ice shelf. Subsequently, the local direction of maximum tensile stress was identified from a linear interpolation of the modelled stresses, and the crack was propagated perpendicular to this direction along a line segment with fixed length. The end point of this segment was marked as the new location of the rift tip, and the process was repeated for updated values of the local stress tensor. Through this algorithm, a fracture trajectory was constructed consisting of line segments with fixed length, and each segment was oriented perpendicular to the local direction of maximum tensile stress. The length of the segments was chosen to be on the order of the minimum mesh resolution, i.e. $250 \mathrm{~m}$, although the algorithm could easily be adapted to allow for a variable step size, based on the local gradients in the stress field or other suitable criteria. It was shown that a step size of $250 \mathrm{~m}$ was sufficiently small for the results to be independent of its exact value. The automated process was iterated for a fixed number of steps or until a certain rift length was reached. It should be noted that the algorithm is diagnostic and does not contain a time com- 

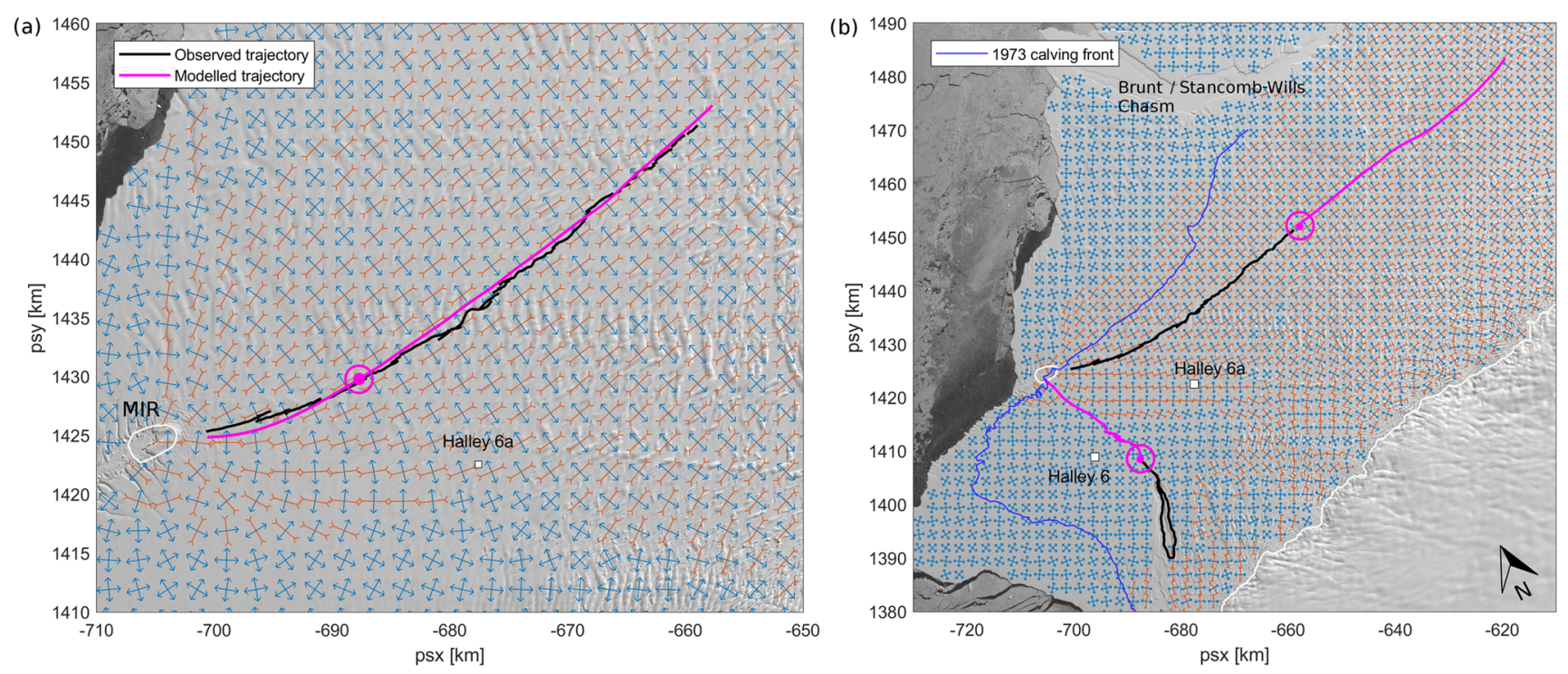

Figure 8. (a) Modelled principal stress components (red are compressive, blue are extensive) in June 2015, resampled on a regular $2.5 \mathrm{~km}$ by $2.5 \mathrm{~km}$ grid. The modelled trajectory of Halloween Crack based on the direction of maximal tensile stress is shown in magenta; the observed trajectory from 15 March 2017 is plotted in black. (b) Modelled principal stress components in March 2017 and predicted future trajectories of Chasm 1 and Halloween Crack. The purple line corresponds to the 1973 calving front.

ponent, nor does it include any dynamic feedback between the formation of the rift and the background stress field.

Two separate inversions were performed with Úa, one for surface velocities in late June 2015, prior to the formation of the HC, and a second inversion for mid-March 2017, after the formation of the HC. The first inversion was used to hindcast the propagation trajectory of the $\mathrm{HC}$ as a way to validate the model and methods, while the second inversion was used to predict the future direction of propagation for Chasm 1 and the $\mathrm{HC}$ using a more recent stress field. Results are discussed in Sects. 4.2 and 4.3, respectively.

\subsection{Model validation}

For validation purposes, the first experiment was designed to hindcast the observed trajectory of the $\mathrm{HC}$ based on the state of stress in the ice shelf shortly before fracture formation in October 2016. For this purpose, a surface velocity field obtained from a Sentinel-1 image pair on 18 and 30 June 2015 (Nagler et al., 2015) was assimilated in Úa. The corresponding tensile stress orientations were used to propagate a crack in opposite directions from the location indicated by the magenta circle in Fig. 8a, which corresponds to the location where the $\mathrm{HC}$ was first observed. The resulting trajectory is shown by the magenta line in Fig. 8a and follows the observed extent of the $\mathrm{HC}$ (in black) to within $1 \mathrm{~km}$ along its entire length. This excellent agreement between model results and observations underlines the validity of the simple fracture propagation algorithm and provides confidence in the predictive skills of the method. Localized deviations from the observed rift trajectory are likely caused by the in- teraction of the rift with spatial variations in ice properties, such as fracture toughness, that cannot be captured by a propagation algorithm based on stress directions alone.

The principal stress rosettes in Fig. 8a (red arrows are compressive, blue arrows are extensive) display a radially symmetric pattern around the MIR, with compressive stresses at oblique angles to the flow in the upstream direction, and compensating tensile stresses perpendicular to the flow. This pattern is generated by the point-interaction between the ice shelf and the bedrock at the MIR and has resulted in the radially outward growth of the $\mathrm{HC}$, perpendicular to the tensile stresses.

The success of the algorithm relies on an accurate representation of the stresses in the ice shelf, which largely depends on the accuracy of the inversion procedure in Úa. The mean residual and standard deviation between observed and modelled surface speeds for the BIS was found to be $1.4(16.6) \mathrm{myr}^{-1}$ or $0.2(4) \%$, which is a significant improvement over De Rydt et al. (2015) and Gudmundsson et al. (2017) due to recent improvements in the inversion procedure in Úa and over Larour et al. (2014), who found a best match for the BIS of around $10 \%$. A priori, the calculated fracture trajectories depend on the amount of regularization $\left(\lambda_{\text {AGlen }}\right)$ and the model resolution. Sensitivity tests were carried out for both variables and the final trajectories of the $\mathrm{HC}$ were found to be independent of the exact value of $\lambda_{\text {AGlen }}$ and mesh resolution. A further reduction of the regularization and additional mesh refinement did not significantly change the results, and only for a much coarser mesh ( $2 \mathrm{~km}$ nodal separation) or a much larger amount of regularization $\left(\lambda_{\text {AGlen }}>10^{5}\right)$ did the modelled trajectories start 
to deviate from the observed trajectory. It should be noted that this result is case specific, and robustness of the fracture trajectories should be considered on a case-by-case basis, in particular for applications with a more complex stress distribution.

\subsection{Future fracture propagation}

The second experiment was designed to propagate Chasm 1 and the $\mathrm{HC}$ beyond their present-day extent, based on the stress distribution in the ice shelf after the formation of the HC. The model domain was adjusted for a minor advance of the ice front between 2015 and 2017, and updated outlines of Chasm 1 and the HC for 15 March 2017 were introduced as gaps in the mesh. Surface velocities in Úa were optimized to match observed velocities based on a pair of Sentinel1 images acquired on 9 and 15 March 2017, with a final residual between observed and modelled surface speeds of $-2.4 \pm 13.5 \mathrm{~m} \mathrm{yr}^{-1}$ or $-0.2 \pm 2.6 \%$.

The model domain was seeded with initial fractures at the tips of the HC and Chasm 1, indicated by the magenta circles in Fig. 8b. The rifts were propagated perpendicular to the direction of maximum tensile stress, up to the edge of the model domain for Chasm 1 and for a total length of $50 \mathrm{~km}$ for the HC, as shown by the magenta lines in Fig. 8b. According to these trajectories, the $\mathrm{HC}$ is expected to continue along its current west-east trajectory towards the StancombWills Glacier Tongue, cutting across a region with uniform tensile stresses that are aligned north-south perpendicular to the grounding line and second principal stresses that are compressive throughout. The estimated trajectory therefore cuts deep into an area of buttressed ice, which could have important implications for the structural integrity of the ice shelf (Doake et al., 1997; Fürst et al., 2016). Note that the estimated trajectory was ended after $50 \mathrm{~km}$ because of possible interactions with the active Brunt-Stancomb-Wills Chasm (see Fig. 8b and Anderson et al., 2014), which could affect the growth of the $\mathrm{HC}$ in uncertain ways.

Furthermore, based on the current stress configuration, the model predicts a continued propagation of Chasm 1 towards the MIR, as shown in Fig. 8b. The path passes through a region with extensive stresses in both principal directions before cutting into the compressive stress region south of the MIR, which could give rise to a possible further reduction in buttressed ice.

\section{Discussion}

Rift propagation in ice shelves is a timely subject and an important process that is often ignored in studies of future ice loss from the Antarctic continent due to the large uncertainties associated with the prediction of rift formation and propagation and the lack of an adequate theoretical description or "calving law". In this work, a number of observations have been made, which confirm or refute findings in earlier work and highlight the complexity of the subject.

Widening rates of both Chasm 1 and the $\mathrm{HC}$ accelerate with rift extension, consistent with previous observations and modelling work by Larour et al. (2004a, b) and Joughin and MacAyeal (2005). Based on the unique time series of baseline measurements across Chasm 1 and the $\mathrm{HC}$, presented in Figs. 2 d, 4 b and $4 c$, we postulate that over the measurement period, widening rates follow an approximately linear relationship in time:

$\frac{\partial w(x, t)}{\partial t}=w_{0}(x)+w_{1}(x) t+\varepsilon(x, t)$,

where $w(x, t)$ is the edge-to-edge width of the rift at a location $x \leq x_{\text {tip }}(t)$ along the rift. The origin $x=0$ corresponds to the root of the rift, furthest away from the tip. The small residue term, $\varepsilon(x, t)$, incorporates measurement errors as well as second-order effects, which will be discussed below.

The functions $w_{0}(x)$ and $w_{1}(x)$ depend on the distance along the rift and have been measured along five different baselines across Chasm 1, i.e. $M 1-B 2, A_{100}-B_{100}, A_{200}-$ $B_{200}, O 0-N 0$ and $A_{400}-B_{400}$ in Fig. 2d, for a period from January 2016 until January 2017. A regression analysis shows that $w_{0}$ and $w_{1}$ are linearly dependent on $x$ with $R^{2}$ values of 0.997 and 0.948 , respectively, and there is no discernible time dependence over the measurement period of 1 year. In summary, the observational data provide strong evidence for an empirical relationship of the form

$\frac{\partial w(x, t)}{\partial t}=w_{00}+w_{01} x+w_{10} t+w_{11} x t+\varepsilon(x, t)$,

with constant parameters $w_{i j}$.

A preliminary analysis of the second-order effects, which have been absorbed into $\varepsilon(x, t)$ in Eq. (2), reveals a direct relationship between rift widening and the propagation of the rift tip, as well as a clear response to tidal forcing. However, the relative amplitude of such effects, i.e. $|\varepsilon| /\left|\frac{\partial w}{\partial t}\right|$, is less than $4 \%$ and therefore negligible. In particular, the propagation of the rift tip, which happens in alternating phases of slow and fast movement in response to spatially variable properties of the ice shelf, has no important influence on the widening rates, and we find no evidence for a stick-slip mechanism of tip propagation as proposed by Larour et al. (2004a). However, we can also not exclude this mechanism based on current data, and alternative methods such as passive seismic measurements might be able to shed more light on this question. A more detailed analysis of the secondorder variability will be presented elsewhere, but, based on the data presented here, we conclude that rift widening is a slowly accelerating process without any clear periodicity, driven by the large-scale distribution of stresses in the ice shelf.

Moreover, in contrast to observations by Fricker et al. (2005), the dynamics of Chasm 1 show no clear seasonal variability superimposed on the multi-year linear trend, and 
it is unclear whether Chasm 1 and the $\mathrm{HC}$ are affected by ice melange that fills the rifts, a mechanism that was put forward by Larour et al. (2004b). During austral summer, open water has been regularly observed at the bottom of both rifts, suggesting that widening rates are too fast for the formation of sea ice to close any potential leads and have any net effect on the stresses.

Based on the tensile stress distribution in the ice shelf, we were able to predict the path of the $\mathrm{HC}$ with remarkable accuracy, and future trajectories have been put forward for testing against new observations. In order to achieve such accuracy, observations were assimilated into an ice flow model, and trajectories were calculated from the modelled stresses. Although principal strain rate directions from remote sensing velocity data could be used as an alternative to estimate the fracture propagation direction, such datasets typically suffer from a low signal-to-noise ratio, and the model effectively acts as a filter to reduce the noise. The suggested propagation algorithm makes use of the direction of maximum tensile stress and is only applicable to existing rifts with known tip location. Observations have shown that the stress magnitudes are not a good indicator for the formation of new rifts or for predicting future propagation.

The future shape of the ice shelf follows from the projected fracture trajectories, and the future of the BIS is most critically dependent on the amount of ice that is lost directly at the MIR, as it controls the reduction in buttressing and corresponding changes in stress over the rest of the ice shelf. During a previous calving event that took place between 1968 and 1971, a rift formed in a location similar to the HC, as shown in Fig. $8 \mathrm{~b}$ by the outline of the ice front derived from a Landsat 1 image on 1 January 1973, shortly after the calving event. At that time, the ice shelf lost a considerable amount of ice at the MIR and doubled its speed in response (Simmons and Rouse, 1984a), although the main part of the ice shelf to the south of the MIR remained intact. This scenario is likely to repeat itself as the HC develops into an iceberg, and although the ice front will be substantially further inshore compared to 1973, the amount of ice removed at the MIR could be comparable.

Despite the similarities to the 1970s event, the presentday circumstances on the BIS are unprecedented because of the recent reactivation and uncertain interplay with Chasm 1 . The potential for additional ice loss at the MIR and a further reduction in buttressing due to the propagation of Chasm 1 is evident from the predicted trajectory in Fig. 8b. This could greatly affect the dynamics and structural integrity of the remainder of the ice shelf, and only when the ice shelf maintains contact with the bedrock at the MIR can a readvance and return to fully buttressed conditions be expected in the future.

\section{Conclusions}

We have presented a comprehensive collection of groundbased and remote sensing data, providing a detailed overview of glaciological changes on the Brunt Ice Shelf over the last decade. In particular, the reactivation of Chasm 1 in December 2012 and the formation of the Halloween Crack in October 2016 have been documented in great detail and have provided an unprecedented view on the dynamics of such rifts, commonly found in Antarctica. We presented the acquisition of ground-based radar data with high temporal and spatial resolution in the area of the tip of Chasm 1, showing a complex structure of the rift at its tip, which is invisible on satellite data. Over the measurement period, both Chasm 1 and the Halloween Crack have been widening at a slowly accelerating rate and have propagated deep into the interior of the ice shelf during successive episodes of faster and slower growth, controlled by the heterogeneous structure of the ice shelf. Through the assimilation of observed ice thickness and surface velocity data into a shallow-ice flow model, as well as the use of a simple fracture propagation algorithm based on the stress distribution in the ice shelf, estimates were made for the future propagation direction of both rifts. Results show a conceivable future loss of buttressed ice in contact with the bedrock at the McDonald Ice Rumples, the only pinning point on the ice shelf, which could further contribute to the ongoing dynamic changes. An intensive monitoring programme has been put in place to track such changes, both in austral summer and winter, using GPS stations, ground-based radar measurements and frequent satellite products from Landsat 8 and Sentinel-1/2. These data will continue to be used in modelling activities that aim to enhance our understanding of ice shelf buttressing, rift propagation and calving - processes that are key to the future mass balance of this and many other ice shelves around Antarctica.

Data availability. All GPS and ground penetrating radar data are available upon request from the authors. All data will be made available through the UK Polar Data Center (http://www.bas.ac.uk/data/ uk-pdc/) once collection is complete. The ice shelf velocity products are based on Copernicus Sentinel data made available through the ESA Science Hub. The products are available upon request through http://cryoportal.enveo.at.

Competing interests. The authors declare that they have no conflict of interest.

Acknowledgements. We like to thank two anonymous reviewers and the editor for their valuable insights and suggestions. We are grateful to all staff at Halley Research Station for supporting this work and their great help with instrument servicing and data acquisition. Processing of Sentinel-1 ice velocity maps by ENVEO was 
supported by the Austrian Space Applications Programme/Austrian Research Promotion Agency (FFG) and the ESA Antarctic ice sheet CCI project and with contributions by Markus Hetzenecker and Joanna Ossowska, both at ENVEO. Copernicus Sentinel-1 data were made available through the ESA Sentinel Scientific Data Hub. Jan De Rydt, G. Hilmar Gudmundsson and Edward C. King were partly supported as part of the Polar Science for Planet Earth funding from the Natural Environment Research Council (NERC) to the British Antarctic Survey.

Edited by: Andreas Vieli

Reviewed by: two anonymous referees

\section{References}

Anderson, R., Jones, D. H., and Gudmundsson, G. H.: Halley Research Station, Antarctica: calving risks and monitoring strategies, Nat. Hazards Earth Syst. Sci., 14, 917-927, https://doi.org/10.5194/nhess-14-917-2014, 2014.

Berger, S., Favier, L., Drews, R., Derwael, J.-J., and Pattyn, F.: The control of an uncharted pinning point on the flow of an Antarctic ice shelf, J. Glaciol., 62, 37-45, https://doi.org/10.1017/jog.2016.7, 2016.

Borstad, C., McGrath, D., and Pope, A.: Fracture propagation and stability of ice shelves governed by ice shelf heterogeneity, Geophys. Res. Lett., 44, 4186-4194, https://doi.org/10.1002/2017GL072648, 2017.

Bürgmann, R., Rosen, P. A., and Fielding, E. J.: Synthetic aperture radar interferometry to measure earth's surface topography and its deformation, Annu. Rev. Earth Pl. Sc., 28, 169-209, https://doi.org/10.1146/annurev.earth.28.1.169, 2000.

Chuter, S. J. and Bamber, J. L.: Antarctic ice shelf thickness from CryoSat-2 radar altimetry, Geophys. Res. Lett., 42, 1072110729, https://doi.org/10.1002/2015GL066515, 2015.

De Rydt, J., Gudmundsson, G. H., Rott, H., and Bamber, J. L.: Modeling the instantaneous response of glaciers after the collapse of the Larsen B Ice Shelf, Geophys. Res. Lett., 42, 5355-5363, https://doi.org/10.1002/2015GL064355, 2015.

Depoorter, M. A., Bamber, J. L., Griggs, J. A., Lenaerts, J. T. M., Ligtenberg, S. R. M., van den Broeke, M. R., and Moholdt, G.: Calving fluxes and basal melt rates of Antarctic ice shelves, Nature, 502, 89-92, https://doi.org/10.1038/nature12567, 2013.

Doake, C. S. M., Corr, H. F. J., Rott, H., P., S., and Young, N. W.: Breakup and conditions for stability of the northern Larsen Ice Shelf, Antarctica, Nature, 778-780, https://doi.org/10.1038/35832, 1997.

Favier, L., Pattyn, F., Berger, S., and Drews, R.: Dynamic influence of pinning points on marine ice-sheet stability: a numerical study in Dronning Maud Land, East Antarctica, The Cryosphere, 10, 2623-2635, https://doi.org/10.5194/tc-10-2623-2016, 2016.

Fricker, H. A., Young, N. W., Coleman, R., Bassis, J. N., and Minster, J.-B.: Multi-year monitoring of rift propagation on the Amery Ice Shelf, East Antarctica, Geophys. Res. Lett., 32, https://doi.org/10.1029/2004GL021036, 2005.

Fürst, J. J., Durand, G., Gillet-Chaulet, F., Merino, N., Tavard, L., Mouginot, J., Gourmelen, N., and Gagliardini, O.: Assimilation of Antarctic velocity observations provides evidence for uncharted pinning points, The Cryosphere, 9, 1427-1443, https://doi.org/10.5194/tc-9-1427-2015, 2015.

Fürst, J. J., Durand, G., Gillet-Chaulet, F., Tavard, L., Rankl, M., Matthias, B., and Gagliardini, O.: The safety band of Antarctic ice shelves, Nat. Clim. Change, 6, 479-482, https://doi.org/10.1038/nclimate2912, 2016.

Glasser, N. F., Kulessa, B., Luckman, A., Jansen, D., King, E. C., Sammonds, P. R., Scambos, T. A., and Jezek, K. C.: Surface structure and stability of the Larsen C ice shelf, Antarctic Peninsula, J. Glaciol., 55, 400-410, https://doi.org/10.3189/002214309788816597, 2009.

Goldstein, R. M., Engelhardt, H., Kamb, B., and Frolich, R. M.: Satellite radar interferometry for monitoring ice sheet motion: application to an Antarctic ice stream, Science, 262, 1525-1530, https://doi.org/10.1126/science.262.5139.1525, 1993.

Gudmundsson, G. H., Krug, J., Durand, G., Favier, L., and Gagliardini, O.: The stability of grounding lines on retrograde slopes, The Cryosphere, 6, 1497-1505, https://doi.org/10.5194/tc-61497-2012, 2012.

Gudmundsson, G. H., De Rydt, J., and Nagler, T.: Five decades of strong temporal variability in the flow of Brunt Ice Shelf, Antarctica, J. Glaciol., 63, 164-175, https://doi.org/10.1017/jog.2016.132, 2017.

Hulbe, C. L., LeDoux, C., and Cruikshank, K.: Propagation of long fractures in the Ronne Ice Shelf, Antarctica, investigated using a numerical model of fracture propagation, J. Glaciol., 56, 459472, 2010.

Ingraffea, A. R.: Theory of crack initiation and propagation in rock, Fracture mechanics of rock, 10, 93-94, 1987.

Jansen, D., Luckman, A., Kulessa, B., Holland, P. R., and King, E. C.: Marine ice formation in a suture zone on the Larsen $\mathrm{C}$ Ice Shelf and its influence on ice shelf dynamics, J. Geophys. Res.-Earth, 118, 1628-1640, https://doi.org/10.1002/jgrf.20120, 2013.

Joughin, I. and MacAyeal, D. R.: Calving of large tabular icebergs from ice shelf rift systems, Geophys. Res. Lett., 32, https://doi.org/10.1029/2004GL020978, 2005.

Khazendar, A., Rignot, E., and Larour, E.: Roles of marine ice, rheology, and fracture in the flow and stability of the Brunt/Stancomb-Wills Ice Shelf, J. Geophys. Res.-Earth, 114, https://doi.org/10.1029/2008JF001124, 2009.

King, E. C., De Rydt, J., and Gudmundsson, G. H.: The internal structure of the Brunt Ice Shelf from ice-penetrating radar analysis and implications for ice shelf fracture, The Cryosphere Discuss., in press, 2018.

Konovalov, G. V.: Deflation hollows on the Lazarev Ice Shelf, Sovetskaya Antarkticheskaya Ekspeditsiya, Informatsionnyy Byulleten, 39, 9-12, 1964.

Larour, E., Rignot, E., and Aubry, D.: Processes involved in the propagation of rifts near Hemmen Ice Rise, Ronne Ice Shelf, Antarctica, J. Glaciol., 50, 329-340, 2004a.

Larour, E., Rignot, E., and Aubry, D.: Modelling of rift propagation on Ronne Ice Shelf, Antarctica, and sensitivity to climate change, Geophys. Res. Lett., 31, https://doi.org/10.1029/2004GL020077, 2004b.

Larour, E., Khazendar, A., Borstad, C. P., Seroussi, H., Morlighem, M., and Rignot, E.: Representation of sharp rifts and faults mechanics in modeling ice shelf flow dynamics: application to Brunt/Stancomb-Wills Ice Shelf, 
Antarctica, J. Geophys. Res.-Earth, 119, 1918-1935, https://doi.org/10.1002/2014JF003157, 2014.

Lawn, B.: Fracture of Brittle Solids, 2nd edn, Cambridge Univ. Press, New York, 1993.

Matsuoka, K., Hindmarsh, R. C., Moholdt, G., Bentley, M. J., Pritchard, H. D., Brown, J., Conway, H., Drews, R., Durand, G., Goldberg, D., Hattermann, T., Kingslake, J., Lenaerts, J. T., Martín, C., Mulvaney, R., Nicholls, K. W., Pattyn, F., Ross, N., Scambos, T., and Whitehouse, P. L.: Antarctic ice rises and rumples: their properties and significance for icesheet dynamics and evolution, Earth-Sci. Rev., 150, 724-745, https://doi.org/10.1016/j.earscirev.2015.09.004, 2015.

McGrath, D., Steffen, K., Rajaram, H., Scambos, T., Abdalati, W., and Rignot, E.: Basal crevasses on the Larsen C Ice Shelf, Antarctica: implications for meltwater ponding and hydrofracture, Geophys. Res. Lett., 39, https://doi.org/10.1029/2012GL052413, 2012.

Nagler, T., Rott, H., Hetzenecker, M., Wuite, J., and Potin, P.: The Sentinel-1 Mission: new opportunities for ice sheet observations, Remote Sens.-Basel, 7, 9371-9389, https://doi.org/10.3390/rs70709371, 2015.
Pritchard, H. D., Ligtenberg, S. R. M., Fricker, H. A. andVaughan, D. G., van den Broeke, M. R., and L., P.: Antarctic ice-sheet loss driven by basal melting of ice shelves, Nature, 484, 502-505, https://doi.org/10.1038/nature10968, 2012.

Rist, M. A., Sammonds, P. R., Oerter, H., and Doake, C. S. M.: Fracture of Antarctic shelf ice, J. Geophys. Res.-Sol. Ea., 107, ECV 2-1-ECV 2-13, https://doi.org/10.1029/2000JB000058, 2002.

Simmons, D.: Flow of the Brunt Ice Shelf, Antarctica, derived from Landsat images, 1974-1985, J. Glaciol., 32, 252-254, https://doi.org/10.1017/S0022143000015586, 1986.

Simmons, D. and Rouse, J.: Accelerating Flow of the Brunt Ice Shelf, Antarctica, J. Glaciol., 30, 377-380, https://doi.org/10.1017/S0022143000006262, 1984a.

Simmons, D. and Rouse, J.: Geomagnetic measurements made on the moving ICE shelf at Halley, Antarctica, Geophys. Surv., 6, 407-417, https://doi.org/10.1007/BF01465555, 1984b.

Thomas, R. H.: The dynamics of the Brunt Ice Shelf, Coats Land, Antarctica, British Antarctic Survey Scientific Reports, 79, 1973. 